$20 \times 50$

Note

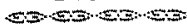

(Received June 21, 1996)

\title{
Radiation-Induced Graft Polymerization of Acrylic Acid onto Poly(3-hydroxybutyrate) and Its Copolymer
}

\author{
Hiroshi Mitomo ${ }^{* 1}$, Tetsuya Sasaoka ${ }^{* 1}$, Fumio Yoshii*2, Keizo Makuuchi*2, and Terumi Saito*3 \\ *1 Department of Biological and Chemical Engineering. Faculty of Engineering. Gunma Uni- \\ versity. Tenjin-cho, Kiryu, Gunma. 376 Japan \\ *2 Japan Atomic Energy Research Institute, Takasaki Radiation Chemistry Research Estab. \\ lishment, Watanuki-cho, Takasaki, Gunma, 370-12 Japan \\ *3 Department of Biological Sciences, Faculty of Science, Kanagawa University, Hiratsuka, \\ Kanagawa, 259-12 Japan
}

\begin{abstract}
A typical hydrophilic monomer, acrylic acid (AAc), was graft polymerized onto poly (3. hydroxybutyrate) (PHB) and its copolymer poly (3-hydroxybutyrate-co-3-hydroxyvalerate) $[\mathrm{P}$ (HB-HV)] by ${ }^{60} \mathrm{Co}-\gamma$-rays preirradiation technique. Degree of grafting $\left(X_{8}\right)$ of PHB was higher than that of the copolym. er of $24 \mathrm{~mol} \% \mathrm{HV}$ content (24M sample). The grafting was mainly introduced into the amorphous regions of the whole samples, while the crystalline regions remained almost unchanged. The $X_{8}$ of the grafted sample estimated by the thermogravimetry was very close to that estimated from weight increase. Biodegradability steeply increased by introduction of small amount of grafted AAc because of the improvement of wettability between the polymer and an enzyme solution, then decreased as $X_{8}$ increased much more.
\end{abstract}

\section{Introduction}

Poly(3-hydroxybutyrate) (PHB) and its copolymer, poly(3-hydroxybutyrate-co-3-hydroxyvalerate) $\quad \mathbb{P}(\mathrm{HB}$ -

HV) ], are biodegradable and biocompatible polyesters produced by many types of bacteria $[1,2]$. In the preceding paper, radiation-induced grafting of methyl methacrylate (MMA) or 2-hydroxyethyl methacrylate (HEMA) monomer onto $\mathrm{PHB}$ and $\mathrm{P}(\mathrm{HB} \cdot \mathrm{HV})$ has been reported [3].

In the present study, acrylic acid (AAC) which is a typical hydrophilic monomer, was graft polymerized onto PHB and P (HB-HV) by preirradiation techniques from a ${ }^{60} \mathrm{Co}-\gamma$-ray source. Degree of grafting, thermal properties and biodegradability of grafted samples were examined.

\section{Experimental}

PHB and P(HB-HV) of 24 mol\% HV (hereinafter called as $24 \mathrm{M}$ sample) were purchased from Aldrich Chemical Co. and used without further purification. The radiation-induced graft polymerization was carried out by a preirradiation grafting method described previously
[3]. The polymers (flaky powder) sealed in evacuated glass ampules were preirradiated to $5 \mathrm{kGy}$ (dose rate of $10 \mathrm{kGy} / \mathrm{h}$ ) at $-78{ }^{\circ} \mathrm{C}$. The $10 \% \mathrm{AAc}$ aqueous solution was introduced to the preirradiated polymers in vacuum to graft polymerize at a constant temperature for various periods of time. Both polymers grafted were extracted with hot water. Degree of grafting $\left(X_{g}\right)$ was obtained by percent increase in weight after grafting.

$$
\mathrm{X}_{8}(\%)=\left[\left(\mathrm{W}_{\mathrm{g}}-\mathrm{W}_{\mathrm{i}}\right) / \mathrm{W}_{\mathrm{i}}\right] \times 100
$$

where $W_{i}$ and $W_{k}$ are weights of the initial and the grafted samples, respectively.

The melting point $T_{m}$ and glass transition temperature $T_{\mathrm{g}}$ of the grafted samples ( $3 \mathrm{mg}$ ) were studied in a Perkin-Elmer Model DSC-7 differential scanning calorimeter (DSC) at a heating rate $10^{\circ} \mathrm{C} / \mathrm{min}$ under nitrogen atmosphere. The melting peak temperature, after calibrated with high-purity standards, was defined as $T_{m}$ with an accuracy within $\pm 0.1{ }^{\circ} \mathrm{C}$. Thermogravimetry (TG) and differential thermal analysis (DTA) of the samples ( 5 $\mathrm{mg}$ ) were simultaneously carried out in a Shimadzu DT. 30 at a heating rate of $10^{\circ} \mathrm{C} / \mathrm{min}$ under nitrogen atmos. phere.

Since the AAc grafted powder sample was difficult to 


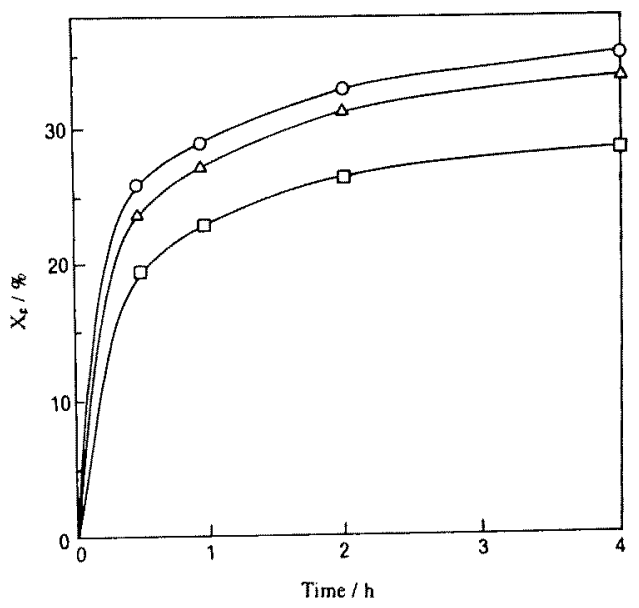

Fig. 1 Plot of grafting degree $\left(X_{B}\right)$ of $A A c$ to PHB against polymerization time at various temperatures: $0^{\circ} \mathrm{C}$ $(\square) .25^{\circ} \mathrm{C}(\triangle), 50^{\circ} \mathrm{C}(\mathrm{O})$

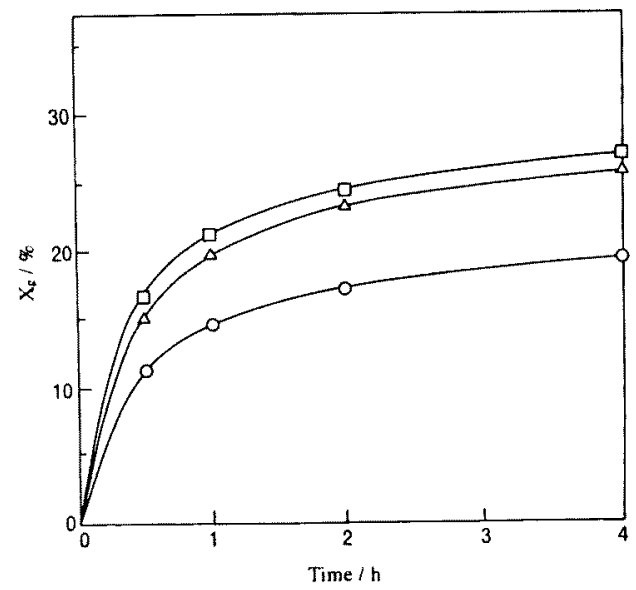

Fig. 2 Plot of $X_{R}$ for $24 M$ sample grafted with $A A c$ against polymerization time at various temperatures: $0{ }^{\circ} \mathrm{C}$ $(\square), 25^{\circ} \mathrm{C}(\triangle), 50^{\circ} \mathrm{C}(\mathrm{O})$

reform the film by molding or solution casting, the meltquenched film (which was aged to crystallize completely) was used for graft polymerization and biodegradability test. The test was carried out at $37{ }^{\circ} \mathrm{C}$ in a $0.1 \mathrm{M}$ phosphate buffer $(\mathrm{pH} 7.4)$ of PHB depolymerase purified from Alcaligenes feacalis $\mathrm{T} 1$ as reported [1]. The reaction was started by adding $1 \mathrm{~mL}$ of aqueous solution of PHB depolymerase (net weight : $8 \mu \mathrm{g}$ ), and biodegradability was represented using the

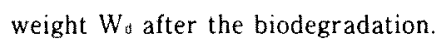

Weight loss $(\%)=\left[\left(W_{g}-W_{d}\right) / W_{g}\right] \times 100$

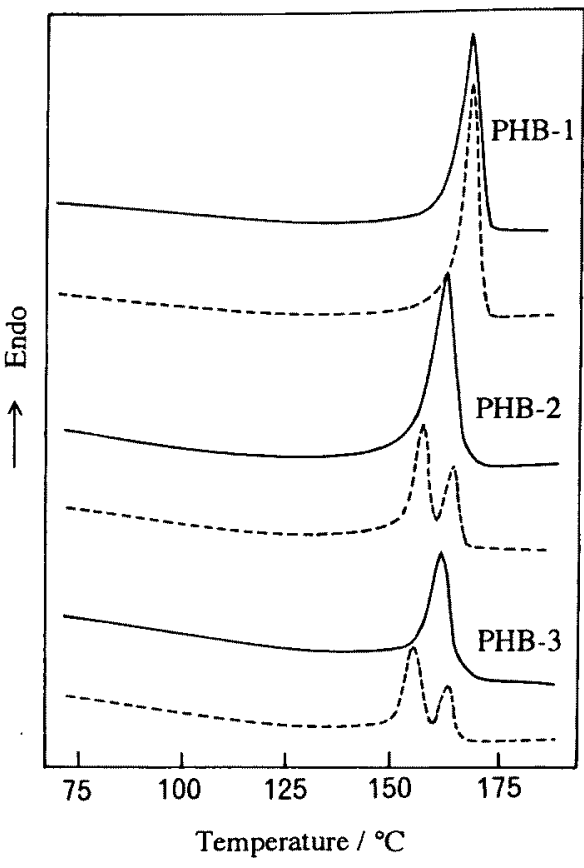

Fig. 3 DSC thermograms of typical PHB samples grafted with AAc (the same notation as used in Table 1). The second run of DSC heating curve for each sample is shown as a broken line.

\section{Results and Discussion}

Figures 1 and 2 show $\mathrm{X}_{\mathrm{B}}$ for $\mathrm{PHB}$ and $24 \mathrm{M}$ samples at various temperatures, respectively. The maximum $X_{B}$ values were $35 \%$ at $25^{\circ} \mathrm{C}$ for $\mathrm{PHB}$ and $27 \%$ at $0{ }^{\circ} \mathrm{C}$ for $24 \mathrm{M}$. In the preceding paper, the maximum $X_{8}$ values of MMA were ca. $120 \%$ at $50{ }^{\circ} \mathrm{C}$ for PHB and $50 \%$ at $25{ }^{\circ} \mathrm{C}$ for $24 \mathrm{M} \mathrm{[} 3$ ]. It is considered that the grafting was mostly introduced into the amorphous regions of the whole sample as seen below. The $\mathrm{X}_{\mathrm{g}}$ of PHB is higher than that of $24 \mathrm{M}$ although the crystallinities of PHB and $24 \mathrm{M}$ are ca. 75 and $50 \%$ (density or X-ray methods), respectively (4). This is explained that life time of the radical generated in crystalline regions is far longer than that in amorphous regions so that former radical retardingly $\mathrm{mi}$ grates to the crystal surface and acts more efficiently than the latter ( 3 ]. Temperatures of the maximum reac. tion rate for $\mathrm{PHB}$ and $24 \mathrm{M}$ samples were positioned to the temperature balancing the lower temperature for low. er radical decay and the higher one for higher polymerization rate. The graft polymerization of MMA was terminated within $30.60 \mathrm{~min}(3)$, while that of AAC 
Table 1 Enthalpies of Fusion $\left(\Delta \mathrm{H}_{\mathrm{m}}\right)$ and Melting Points $\left(\mathrm{T}_{\pi}\right)$ of PHB and $24 \mathrm{M}$ Samples Grafted with AAC

\begin{tabular}{ccccccc}
\hline $\begin{array}{c}\text { Sample } \\
\text { No. }\end{array}$ & prunk & $\mathrm{X}_{\mathrm{B}}$ & $\Delta \mathrm{H}_{\mathrm{m}}$ & $\left(\Delta \mathrm{H}_{\mathrm{m}}\right)_{\text {corr }}$ & $\mathrm{T}_{\mathrm{m}}$ & $\mathrm{T}_{\mathrm{g}}$ \\
\hline PHB-1 & PHB & 0.0 & 77.8 & 77.8 & 171.0 & 1.0 \\
PHE.2 & PHB & 19.4 & 67.9 & 75.2 & 16.4 .7 & 2.8 \\
PHB.3 & PHB & 32.8 & 61.6 & 74.5 & 164.7 & 4.0 \\
& & & & & & \\
$24 \mathrm{M}-1$ & $24 \mathrm{M}$ & 0.0 & 51.4 & 51.4 & 128.8 & -26 \\
$24 \mathrm{M}-2$ & $24 \mathrm{M}$ & 15.2 & 41.1 & 47.3 & 127.2 & -1.7 \\
$24 \mathrm{M}-3$ & $24 \mathrm{M}$ & 24.5 & 34.5 & 43.0 & 125.1 & -1.0 \\
\hline
\end{tabular}

continued to take place considerably even after $4 \mathrm{~h}$. These differences are caused by diffusibility of monomers or radical decay in $10 \%$ aqueous AAc solution and bulk MMA solution.

Figure 3 shows DSC thermograms of typical PHB samples grafted with AAc. The sample number used is the same notation as that in Table 1. The $T_{m}$ and peak area $\left(\Delta \mathrm{H}_{\mathrm{m}}\right)$ of PHB slightly decreased with AAC graft polymerization. DSC heating curves (second run) for the samples once heated up to $190^{\circ} \mathrm{C}$ then cooled down $(10$ $\mathrm{C} / \mathrm{min}$ ) to room temperature were shown with dashed lines, whose melting peaks became doublet for the grafted samples. The doublet peak implies the formation of two crystal modifications, i.e., the original crystal modification appearing at higher temperature and the one at the lower temperature reflecting the crystal regions more disordered by partially occlusion of grafted polym. er chains

Table 1 shows melting points $\left(T_{m}\right)$. glass transition temperatures $\left(\mathrm{T}_{\mathrm{g}}\right)$ and enthalpies of fusion $\left(\Delta \mathrm{H}_{\mathrm{m}}\right)$ of PHB and $24 \mathrm{M}$ samples grafted with AAc (PHB-1 and $24 \mathrm{M}-1$ are original). The $\Delta \mathrm{H}_{m}$ may be corrected by the weight fraction of trunk polymer in the grafted samples according to the following equation :

Corrected enthalpy of melting $\left(\Delta \mathrm{H}_{m}\right)_{\mathrm{cor}}=\Delta \mathrm{H}_{\mathrm{m}}\left(1+\mathrm{X}_{\mathrm{B}}\right)$

The $\left(\Delta H_{m}\right)_{\text {cort }}$ values for both grafted samples remained almost unchanged though $T_{m}$ values decreased slightly. The $\mathrm{T}_{\mathrm{B}}$ values of both samples increased to $2-3{ }^{\circ} \mathrm{C}$ as the $X_{R}$ increased to $25.35 \%$. These results imply that grafting with AAC was almost uniformly introduced to amorphous regions of the whole sample.

Figure 4 shows typical TG/DTA thermograms of PHB and $24 \mathrm{M}$ samples grafted with AAc. In DTA curves,

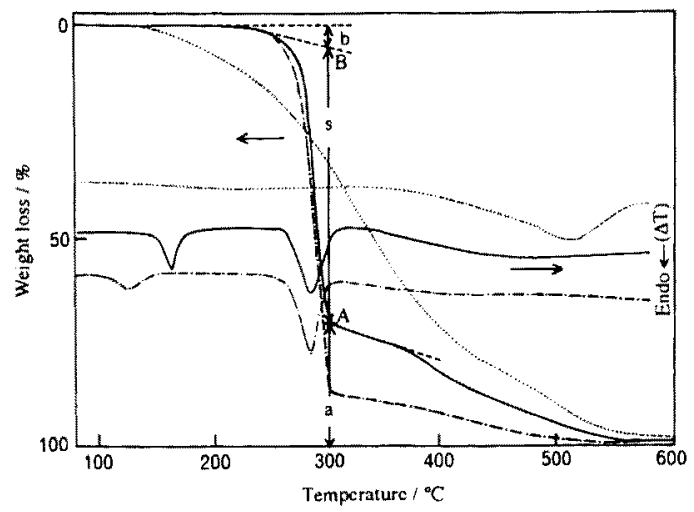

Fig. 4 TG thermograms of PHB (- - ) and 24M (- - samples grafted with AAC. The TG thermogram of $\mathrm{P}$ (AAC) homopolymer is shown as the dashed line.

PHB-3 and $24 \mathrm{M} \cdot 2$ samples show melting peaks appearing at 165 and $127^{\circ} \mathrm{C}$, respectively, and $\mathrm{P}(\mathrm{AAc})$ show no melting peak. In TG curves, PHB sample completely de. composed at the temperature range of $240-290^{\circ} \mathrm{C}$, while $24 \mathrm{M}$ sample decomposed at the range of 5-10 $\mathrm{C}$ lower than the former. The P (AAC) homopolymer decomposed over a wide temperature range of $130-600^{\circ} \mathrm{C}$ as shown in a dashed line. Typical grafted samples show two step of weight loss curves : the first drop corresponding to the sum of both the trunk polymers which are completely decomposed at ca. $300^{\circ} \mathrm{C}$ and the $\mathrm{P}(\mathrm{AAC})$ graft polymer, and the second drop corresponding to the sole $P$ (AAC) graft polymer. TG curves of the graft samples shifted up to ca. $10^{\circ} \mathrm{C}$ higher, reflecting the thermal stability similar to the case of MMA grafting (3). In DTA curves, all samples show decomposition peaks at the temperatures corresponding to the weight loss curves.

The $X_{8}$ is also estimated from these $T G$ curves [5] One example for PHB was shown in Fig.4. The point $A$ was obtained as an intersection of the steepest tangent of the first drop with the gentlest line of the plateau of the second drop. The point $B$ was obtained as an intersection of the tangent at $240{ }^{\circ} \mathrm{C}$, where is just before the decom position tenperature of $\mathrm{PHB}$, with the vertical line at point $A$. The weight of $\mathrm{PHB}$ is shown by $\mathrm{AB}$ (or $\mathrm{s}$ ) and that of the $P(A A C)$ graft polymer is shown by the sum of the depth of point $B$ (or $b$ ) and the height of $A$ (or $a$ ), and degree of grafting $X_{k}$ is given by the following equa. tion.

$$
X_{s}=[(a+b) / s] \times 100
$$




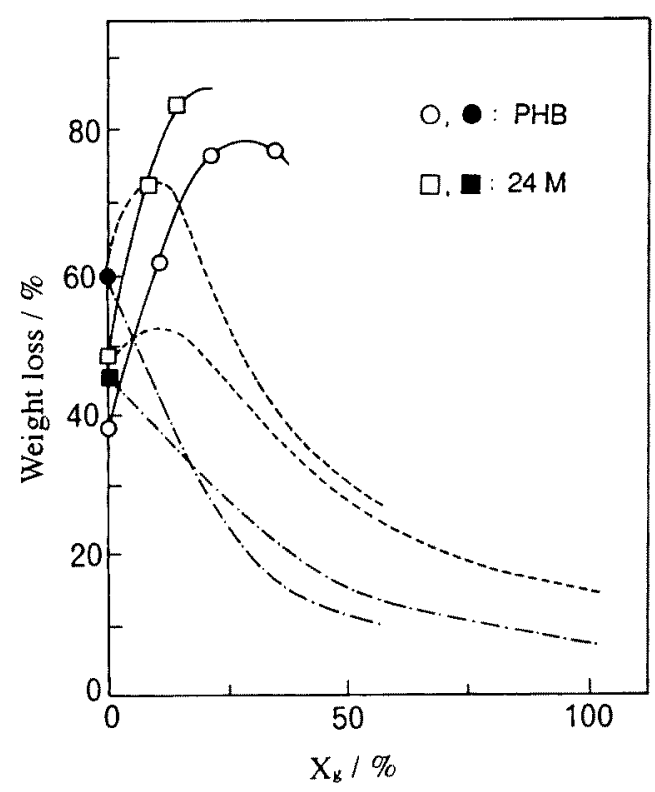

Fig. 5 Comparison of weight loss values of PHB $(\bigcirc)$ and $24 \mathrm{M}(\square)$ samples grafted with $A A c$ in the enzymatic degradation test. The weight loss values of PHB

and $24 \mathrm{M}$ ( $\square$ ) samples grafted with MMA (-_-_- $)$ ) and HEMA (.......) are also shown.

The $X_{\mathbb{8}}$ values estimated from Eq. (4) were very close to the values obtained from weight increase using the Eq. (1)

Figure 5 shows the results of enzymatic degradation test. The $X_{g}$ values for both film samples were almost similar to those for powder samples. Weight loss rate of $24 \mathrm{M}$ is faster than that of PHB because of the strongly promoted biodegradation with the lower crystallinity [6], though that of PHV per se is pretty slower than that of PHB [1]. The activity of the enzyme seems to drop as the treatment time became longer. whose phenomena is frequently observed at our previous results $[3,7]$, therefore the time was fixed to 24 h. Fig. 5 shows the comparison of biodegradability of PHB and $24 \mathrm{M}$ samples grafted with MMA, HEMA and AAc. After grafting with MMA or HEMA, the samples were reformed to solu. tion casted film, while the samples used for grafting with AAc were the melt-quenched film prior to grafting and used without further reforming. Biodegradation was suppressed by introduction of MMA grafting which is hyd. rophobic, while it was promoted by introduction of HEMA grafting which is hydrophilic (3). PHB became more hydrophilic by grafting with AAc than that with HEMA, therefore, wettability of film sample with enzyme solution was more improved, which results in promotion of biodegradability. Moreover, the grafted P(AAc) was dessolved into the solution after the trunk polymer was completely hydrolyzed by the enzyme. This results in apparently further weight loss of the whole sample.

Thus, biodegradability was promoted by introduction of small amount of AAC grafting, i.e., $\mathrm{X}_{\approx}$ range of 20 . $30 \%$. However, if the samples are graft polymerized to larger $\mathrm{X}_{8}$ above $50 \%$ though it is difficult to prepare, then that is supposed to show a steep decrease curve almost parallel to those grafted with HEMA because $P$ (AAc) and P(HEMA) per se are not biodegradable pol. ymers.

\section{References}

1. Y. Doi, Y. Kanesawa, and M. Kunioka, Macromolecules, 23, 26(1990).

2. W. Korsatko, Pharm. Ind., 46, 952 (1984).

3. H. Mitomo, T. Enjōji, Y. Watanabe, F. Yoshii, K. Makuuchi, and T. Saito, J. Macromol. Sci.Pure Appl. Chem., A32, 429(1995).

4. H. Mitomo, N. Morishita, and Y. Doi, Polymer, 36, $2573(1995)$.

5. H. Mitomo, Netsu Sokutei, 23, 98 (1996).

6. Y. Kumagai and Y. Doi, Makromol. Chem., 193, 53 (1992).

7. K. Bahari, H. Mitomo, T. Enjôji, S. Hasegawa, F. Yoshii, and K. Makuuchi, Angew. Makromol. Chem., (in press). 